\title{
FACTORS INFLUENCING MOBILE-LEARNING ADOPTION INTENTION: AN EMPIRICAL INVESTIGATION IN HIGH EDUCATION
}

\author{
Ngo Tan Vu Khanh and Gwangyong Gim \\ School of Business, Soongsil University, Seoul-Korea
}

Received 2014-05-20; Revised 2014-06-12; Accepted 2014-07-02

\begin{abstract}
This study investigates the use of mobile phones and tablets for learning purposes among university students in Vietnam. For this purpose, the research is based on relevant technology acceptance literature and the Technology Acceptance Model (TAM) is proposed to analyze the adoption of mobile devices and smart phones by Vietnam students for accessing course materials, searching the web for information related to their discipline, sharing knowledge, conducting assignments etc. Employing structural equation modeling (SEM) technology, the model was assessed based on the data collected from 301 participants using a survey questionnaire. These results validate the power of TAM constructs and its appropriateness for predicting acceptance of mobile learning. Usefulness had the highest path coefficients and was a strong predictor of behavioral intention and attitude to use and thus actual use. The proposed TAM model also can improve the understanding of students' motivation by suggesting what external factors are the most important in enhancing students acceptance of mobile learning.
\end{abstract}

Keyword: Knowledge Translation, TAM, Mobile Learning, Vietnam, ICT Education

\section{INTRODUCTION}

Education is a key investment in human capital: No variable over the long run better explains economic success than investment in education. With developing world SIM connections exceeding 5 billion in 2012, the opportunity for Mobile Learning and Education to overcome barriers to traditional learning such as accessibility and cost moves ever closer to becoming a reality. Mobile services are increasingly spreading and dominating many aspects of our life worldwide. According to the Vietnam Internet Network Information Center, Vietnam ranks 18/20 countries with the largest number of Internet users in the world, ranking eighth Asia and ranks third in Southeast Asia with 31,302,752 Internet users as of Dec 2013, 35.53\% of the population, Recently, Vietnam ICT news is reported as the country with the highest percentage of mobile phone users in the whole globe. According to Google's survey 2013 in
Vietnam, the number of smartphone users accounted for $20 \%$ of the population of Vietnam (17 million peoples). The reported statistics indicate significantly increasing trends among teenagers towards adopting mobile services for use with the Internet applications. Mobile use can offer great opportunities for improving teaching and learning processes among young students. However the benefits gained from mobile services depend on the intention of students to use them for educational purposes. Technology Acceptance Model (TAM) which was originated in the area of information systems, has been widely used to examine examines the perceived usefulness and perceived ease of use as correlated with people's intention to use a system or technology (Davis, 1989). Nowadays, (TAM) has been one of the popular research tools that can help to investigate suchintention and further identify the driving and motivating factors for accepting different technologies. Present a framework of a contextual mobile learning system for

Corresponding Author: Ngo Tan Vu Khanh, School of Business, Soongsil University, Seoul-Korea Tel: +82 10 37446850; Fax: +82 28244384 
Asia Pacific universities environment. The proposed system aims to help the students to learn in their daily lives using mobile computing devices like tablet PCs and Smart Phones. The tipping point for the m-learning industry has probably been reached (Adkins, 2008). Currently m-learning is increasingly used in museums, workplaces and classrooms for learners inside or outside the formal education systems, such as dropouts and the unemployed, enabling a wide spectrum of educational possibilities (Attewell and Savill-Smith, 2003). The reviewed literature have provided important insights into mobile learning adoption, but the issue still needs to be examined from other directions such as the innovativeness and anxiety and other external cultural factors. As mentioned earlier in this paper, the Vietnam Internet Network Information Center is reported as the country with the highest percentage of mobile phone users in the whole globe. In spite of this wide adoption of mobile phones, there is no published research to investigate the adoption of m-learning among Vietnam college students. This paper fills the gap in the literature by extending the classical TAM by adding the perceived mobility value, service quality, student readiness, perceived social interaction value and system commitment to Vietnam students' behavioral intension to use smartphones and tablets for educational-purposes.

As a result the paper sought to answer two key research questions. (i) What are the keys factors motivating students' intention to use m-learning? (ii) Will TAM remain robust in the context of m-learning in comparison with five additional structures? An investigation into the two research questions in the current study would help to identify the most influential factor of m-learning adoption and probably of educational information systems adoption. This paper is organized as follows. In the next section, we briefly introduce the mlearning development in Vietnam and its potentials and challenges faced. Then, theoretical background and the research model are presented, which is followed by a detailed report on the results of the study. Thereafter, results are discussed with a number of implications and conclusions. Finally, limitations of this study and implications for future studies are discussed as well.

\section{THEORETICAL BACKGROUNDS AND THE RESEARCH MODEL}

\subsection{Technology Acceptance Model (TAM)}

Among all the adoption theories, TAM enjoys an excellent reputation with regard to its robustness, parsimony and explanatory power (Davis, 1989). TAM is rooted in the social psychology Theory of Reasoned Action (TRA) (Ajzen and Fishbein, 1980). TRA postulates that beliefs affect attitude, which influences intention, while intention in turn brings about behaviors. TAM adopts this belief-attitude-intention behavior relationship and posits that users' IT acceptance is a function of two cognitive beliefs: Perceived ease of use and perceived usefulness (Davis, 1989). Perceived ease of use refers to the degree to which a user believes that using a particular service would be free of effort. Perceived usefulness is defined as the degree to which an individual perceives that using a particular system would enhance his or her job performance (Davis, 1989). Further, perceived usefulness is influenced by perceived ease of use. The key constructs of TAM have been tested, refined and extended in various contexts since the original publication (Li et al., 2008; Legris et al., 2003), which has resulted in a robust adoption model in particular for utilitarian systems. This research is based on an extended TAM. TAM is selected based on its excellent reputation in terms of robustness and explanatory power (Liu and Arnett, 2010). For more information on TAM interested reader is referred to Davis (1989) and Chun and Yang (2011). The two main constructs upon which the model is built are perceived usefulness and perceived ease of use. In Fig. 1, Davis (1989) defined the two variables as follows:

- Perceived Usefulness (U) is "the degree to which a person believes that using a particular system would enhance his or her job performance"

- Perceived Ease of Use (EoU) is "the degree to which a person believes that using a particular system would be free of effort"

\subsection{Perceived Mobility Value (PMV)}

It illustrates the end-users' awareness of mobility value during their studies of mobile learning. Seppälä and Alamäki (2003) claimed that the mobility value contains convenience, portability and immediacy. Mobility value supports the users to access and check the information needed anywhere at any time through mobile devices. The real-time data would be checked and gained if the end-users have some geographical limitations, which result in the inconveniences of being there. Put another way, the mobility value solves some disabilities and guide users in a new learning situation without when and where limitations (Huang et al., 2007). Thus, mobility value is valuable as a primary concern. 


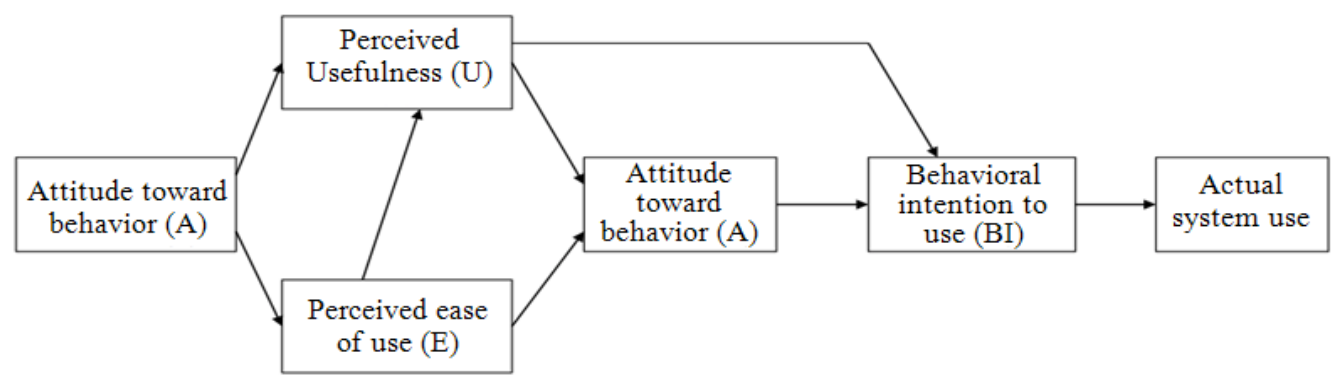

Fig. 1. The Technology Acceptance Model (TAM)

In their study, the perceived mobility value is a factor of individual that has an impact on users' intention and behaviors. The authors treated perceived mobility value as new variable in TAM and also proved their hypothesis as accepted in the researched area (Huang et al., 2007). Therefore, mobility value can be considered as a key influence that has an impact on perceived usefulness towards students' perceptions and attitudes before adoption. Hence, the authors of this research hypothesize that perceived mobility value affects perceived usefulness positively:

H1: Perceived Mobility Value (PMV) has a positive effect on Perceived Usefulness (PU).

\subsection{Student Readiness (SR)}

Student readiness is defined as a student's self perception of being capable to accomplish learning tasks. It is divided into two concepts: Mobile self-efficacy and student commitment (internal). Mobile self-efficacy, newly defined for this research, is based upon the general concept of self efficacy from Bandura $(1982 ; 1977)$ and the concept of computer or web self efficacy investigated by many researchers (Compeau and Higgins, 1995; Park and Chen, 2007; Lopez and Manson, 1997). Bandura (1982) defines self-efficacy as "people's judgments of their capabilities to organize and execute courses of action required to attain designated types of performances" (p. 122) and proposes that measures of self-efficacy should be adapted to the specific behavior and psychological functioning under consideration. Compeau and Higgins (1995) defined the construct of computer self-efficacy as an individual's perception of his/her ability to use a computer in the accomplishment of a task. They developed a reliable and valid instrument to measure computer self-efficacy. Student readiness is hypothesized in this research study to have a direct impact on usefulness and ease of use as well as an indirect impact on attitude and behavioral intention and thus, m-learning acceptance:
H2: Student Readiness (SR) will be positively related to perceived usefulness of mobile learning.

H3: Student Readiness (SR) will be positively related to perceived ease of use of mobile learning.

\subsection{Quality of Service (QoS)}

Quality of service refers reliability and response, content quality, personalization, privacy and security. Many of these concepts are derived from HCI and usability research (Nielson, 1993; Kuan et al., 2003) and IS success models (Delone and Mclean, 1992; Rai et al., 2002). Other concepts are derived from service quality research that was adapted for the Internet and the web such as SERVQUAL (Parasuraman et al., 1994) and its derivatives such as E-S-QUAL (Parasuraman et al., 2005) and WebQual (Barnes and Vidgen, 2002). All of these variables can act as either inhibitors or facilitators of acceptance and use. Lin and Wu (2002) used online service quality "OSQ" as an antecedent to usefulness and ease of use in TAM. OSQ consisted of information content (i.e., easy to understand text, graphics, etc.), customization (i.e., personalized service to understand the customer's needs), reliability and response (i.e., display/transmission/service correctly and in time, online service and problem solving) and security (i.e., security of transmission and privacy protection). Quality of service is hypothesized to have an indirect impact on behavioral intention and thus acceptance of mobile learning through being a direct antecedent of ease of use and usefulness:

H4: Quality of Service (QoS) will be positively related to perceived usefulness of mobile learning.

H5: Quality of Service (QoS) will be positively related to perceived ease of use of mobile learning.

\subsection{Perceived Social Interaction Value (PSIV)}

Perceived social interaction value has not been tested before in the area of mobile learning but has appeared in 
other business and computer based areas. It is also associated with the significant awareness value of students interviewed, which helped gather information needed for questionnaire construction. Lee and Tsai (2010) proposed a theoretical research model by combining the Technology Acceptance Model and theory of Planned Behavior Model, which consists of experience, Human Computer Interaction, Social Interaction and Perceived Enjoyment in computer based gaming. In this study, Social Interaction is considered both a key factor incorporated in TAM model and an external variable, in order to test the hypothesis on usefulness towards acceptance. Dickinger et al. (2008) analyzed the effect of peers on individuals' adoption behavior of a new Voice over Internet Protocol (VoIP) service based on General Packet Radio Service (GPRS) or Enhanced Data rates for GSM Evolution (EDGE). This study exemplifies that the users are not being limited to one-to-one communication but still prefer one-to-many social interaction (Dickinger et al., 2008). The result shows that a high degree of social interaction value plays a significant role on users' perception of usefulness:

H6: Perceived Social Interaction Value (PSIV) has a positive effect on Perceived Usefulness (PU)

\subsection{System Commitment (UC)}

University commitment refers to the widely studied concept of organizational support, or university support in this setting. University support consists of the dimensions of top management support, user training, technical user support, user involvement and product champion (Moore and Benbasat, 1991; Park and Chen, 2007). Training students how to effectively and properly use mobile learning technologies is important during both preand post implementation. Several authors have provided evidence that the level of training positively influences the user's beliefs about a system as well as subsequent usage behavior (Thompson et al., 1994; Igbaria, 1990; 1993). Mobile learning's most prominent benefit is that it offers convenient, anywhere/anytime learning and education (Little, 2006; Trifonova, 2003; Keegan, 2002). M-learning affords students ease of access to learning materials, mobility of both the learner and the learning materials and devices and therefore greater convenience to the student. Training students on the system will enhance their awareness of the system's usefulness and ease of use. This research proposes that the university commitment construct and dimension indirectly influence the acceptance of mobile learning through ease of use and usefulness. This research proposes that the university commitment construct and dimension indirectly influence the acceptance of mobile learning through ease of use and usefulness:

H7: System Commitment (SC) will be positively related to perceived ease of use of mobile learning.

H8: System Commitment (SC) will be positively related to perceived usefulness of mobile learning.

Several testable statements, or hypotheses, can be drawn from the theoretical framework. Based on hypotheses used to study the acceptance of mobile learning are presented next. These research hypotheses will test relationships external to the TAM model as these relationships have been validated in numerous studies as presented earlier. They will also investigate external dimensions related to mobile learning and are depicted in Fig. 2.

\section{RESEARCH METHODOLOGY}

In order to assess the research model, a questionnaire was designed to collect data. The scales used in the questionnaire were largely built upon the scope and structure of previous studies. Constructs were measured based on seven-point Likers-scales ranging from strongly disagree (1) to strongly agree (7). This research services are focused on university students, they accordingly became the target group of the study. The sample was collected from undergraduate students in five top Universities in Ho Chi Minh city (Vietnam) in June 2013. A total of 310 responses were returned from 320 participants giving a response rate of $96.9 \%$. Eight responses were discarded due to being only partially completed. One response, which only has no answer on the question about experience using mobile, was included in analysis as well. The respondents consisted of 160 males and 141 females between 18 and 22 years old. The descriptive statistics of the sample are shown in Table 1. Among the respondents, $86 \%$ have already used mobile phones for more than one year while most of them $(94.4 \%)$ use advanced mobile services at least once per week. Most respondents (67.1\%) have already known what m-learning is before the survey and 21.3 percent of them have even used m-learning before. 


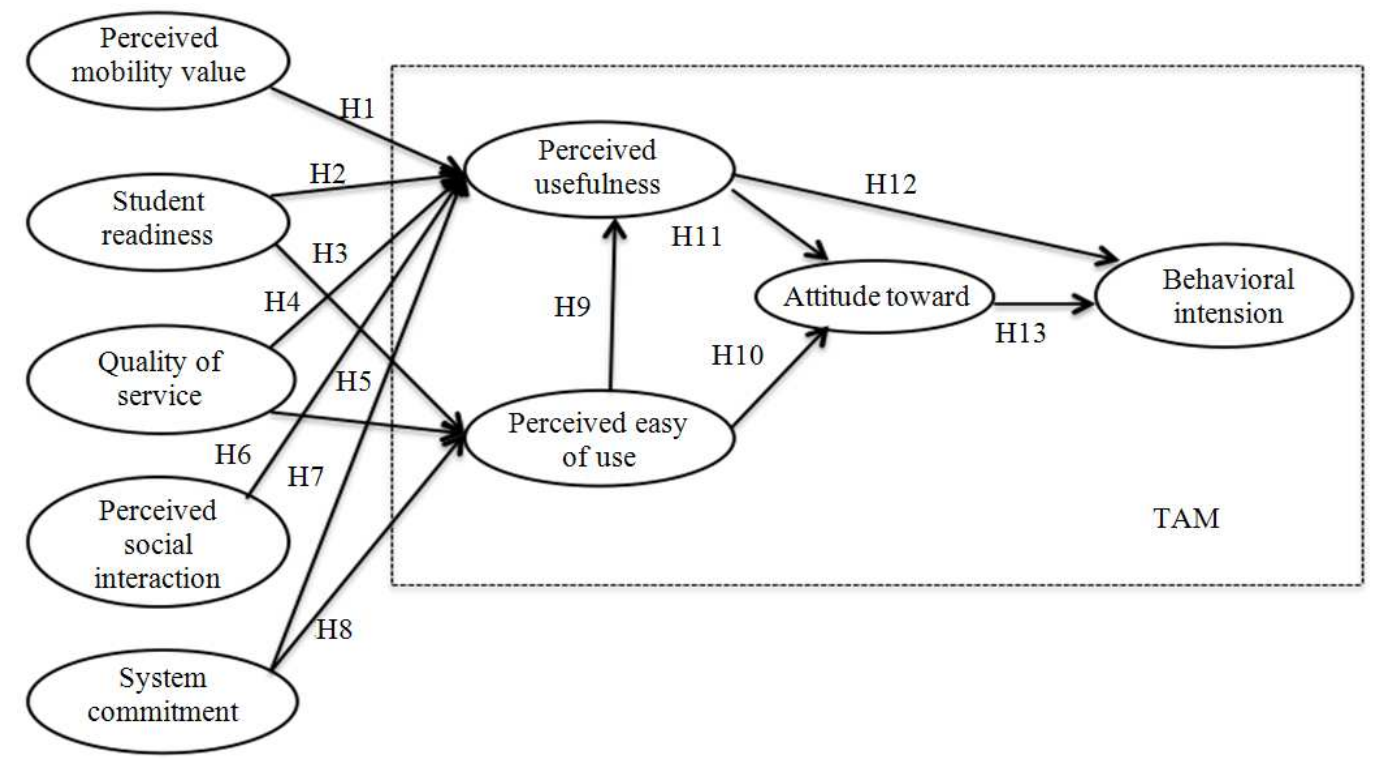

Fig. 2. Research model

Table 1. Demographic information of participants

\begin{tabular}{|c|c|c|}
\hline Demographic profile & Frequency & Percent $(\%)$ \\
\hline \multicolumn{3}{|l|}{ Gender } \\
\hline Male & 160 & 53.1 \\
\hline Female & 141 & 46.9 \\
\hline Total & 301 & 100.0 \\
\hline \multicolumn{3}{|l|}{ Length of time using a smartphone/total (year) } \\
\hline Less than 0.5 & 11 & 3.7 \\
\hline $0.5-1$ & 31 & 10.3 \\
\hline $1-1.5$ & 60 & 19.9 \\
\hline More than 2 & 199 & 66.1 \\
\hline Total & 301 & 100.0 \\
\hline \multicolumn{3}{|c|}{ Frequency of using advanced mobile services (times per week) } \\
\hline Never & 20 & 6.6 \\
\hline $1-5$ & 79 & 26.2 \\
\hline $5-10$ & 132 & 43.9 \\
\hline More than 10 & 70 & 23.3 \\
\hline Total & 301 & 100.0 \\
\hline \multicolumn{3}{|l|}{ Experience } \\
\hline No answer & 1 & 0.3 \\
\hline I do not know what m-learning is and never used it before & 98 & 32.6 \\
\hline I know what m-learning is, but never used it before & 138 & 45.8 \\
\hline I know what m-learning is and used it before & 64 & 21.3 \\
\hline Total & 301 & 100.0 \\
\hline
\end{tabular}

\section{DATA ANALYSIS AND RESULTS}

\subsection{Data Analysis and Result}

All of the constructs in this study were examined in terms of reliability, convergent validity and discriminant validity. Reliability was evaluated using the composite reliability values. Convergent validity indicates the extent to which the measure of a construct that is theoretically related is also related in reality. Convergent validity can be evaluated using three criteria suggested by Fornell and Larcker (1981): (1) All indicator factor 
loadings should be significant and exceed 0.70 , (2) construct reliabilities should exceed 0.80 and (3) Average Variance Extracted (AVE) by each construct should exceed the variance due to measurement errors for that construct. AVE should exceed 0.5 (Fornell and Larcker, 1981). Principal components extraction with Varimax rotation was first conducted to extract five factors using SPSS 20.0. The results show that all items fit their respective factors quite well. All the factor loadings are above the threshold of 0.7. As described in Table 2, the Cronbach's alpha values range from 0.773 to 0.93 , with 9 research concepts (perceived mobility value, student readiness, quality of service, perceived social interaction value, system commitment, perceived of easy to use, perceived of usefulness, attitude toward and behavior intension) are satisfied internal consistency reliability after refining scales: 1 Scale at acceptable level, 6 scales at good level and 2 at excellent level. This indicates that the data were collected by all of nine scales are reliable for the CFA. Confirmative factor analysis was then conducted using AMOS 18.0. The Composite Reliability values (CR) and Average Variance Extracted (AVE) of all the constructs satisfy the recommended level of 0.7 and 0.5 respectively, thereby indicating good internal consistency (Hair et al., 2010).

Discriminant validity can be verified with the square root of the average variance extracted for each construct higher than any correlation between this construct and any other construct (Fornell and Larcker, 1981). As shown in Table 3, the square roots of AVE of all constructs are greater than the correlation estimate with the other constructs. This reveals that each construct is more closely related to its own measures than to those of other constructs and discriminant validity is, therefore, supported in this study (Fornell and Larcker, 1981). The measurement model fit was assessed by a Confirmatory Factor Analysis (CFA). Seven common model-fit measures were used to estimate the measurement model fit: (1) Chi-square/degree of freedom (v2/df), (2) the goodness-of-fit index (GFI), (3) root mean square error of approximation (RMSEA), (4) root mean square residual (RMR), (5) normed fit index (NFI), (6) nonnormed fit index (NNFI) and (7) comparative fit index (CFI). As Table 4 shows, all the model-fit indices satisfy their respective acceptance criteria suggested in the prior literature (Hair et al., 1998). Therefore, we can conclude that the measurement model has good fit with the data collected. Table 4 Also shows the common model-fit indices, recommended values and results of the test of structural model fitness. A comparison of all fit indices with their corresponding recommended values (Hair et al., 2010) indicates a good model fit.

\subsection{Structural Paths Assessment and Hypothesis Test}

To test structural relationships, the hypothesized causal paths were estimated and all seven hypotheses were supported. Table 5 shows these results, which generally support the proposed model and illustrate key roles of usefulness in the model. The results showed the important roles of Quality of service, student readiness and system commitment in determining users' intentions to use mobile learning in Vietnam. Table 5 gives a graphical description of the results including path coefficients and variances explained. Against expectations, perceived mobility value and perceived social interaction value no significant influence on perceived usefulness (PMV ---> PU, $\mathrm{t}=-0.365, \mathrm{p}>0.05$ ), (PSIV ---> PU, $\mathrm{t}=-0.382, \mathrm{p}>0.05)$ which indicates that hypotheses 1 and 6 are not supported. Furthermore, Student readiness also no influence on perceived easy of use (SR ---> PEoU, $\mathrm{t}=-0.736, \mathrm{p}>0.05$ ), which indicate hypotheses 3 is not supported. The results highlight the important roles of system commitment in mobile learning, it showed the greatest effect on perceived usefulness $(\beta=0.6, p<0.001)$. Student readiness and Quality of service also effect on perceived usefulness (SR ---> PU, $\beta=0.36, \mathrm{p}<0.001)$, (QoS ---> PU, $\beta=0.28$, $\mathrm{p}<0.001)$. The model also shows a significant effect of quality of service on perceived easy of use, supporting H5 (QoS ---> PEoU, $\beta=0.45, \mathrm{p}<0.001)$. H6 with the effect of system commitment on perceived easy of use is supported (SC ---> PEoU, $\beta=0.44, \mathrm{p}<0.001$ ), which implies perceived easy of use as a mediating effect on the relation between Quality of service and system commitment. In addition, we can also see the effect of perceived easy of use on perceived usefulness, but not influence on Attitude toward (PEoU ---> PU, $\beta=0.18$, $\mathrm{p}<0.001)$, (PEoU ---> A, $\mathrm{t}=1.161, \mathrm{p}>0.05)$.

Table 5 also illustrates the explanatory powers of constructs. The model finds that perceived easy of use accounts for $36 \%$ of the variance in perceived easy of use. Student readiness, quality of service, system commitment and perceived easy of use, taken together, explain $82 \%$ of the variance in perceived usefulness. In total, the model explains $70 \%$ of the variance in behavioral intention to use mobile learning, which has been shown to be a strong predictor of actual use. 
Ngo Tan Vu Khanh and Gwangyong Gim / Journal of Social Sciences 10 (2): 51-62, 2014

Table 2. The measurement model

\begin{tabular}{|c|c|c|c|c|}
\hline Item & Cronbach's alpha & Standardized factor loading & $\mathrm{CR}$ & AVE \\
\hline PVM1 & 0.807 & 0.848 & 0.84 & 0.64 \\
\hline PVM2 & & 0.729 & & \\
\hline PVM3 & & 0.812 & & \\
\hline SR1 & 0.832 & 0.718 & 0.84 & 0.52 \\
\hline SR2 & & 0.718 & & \\
\hline SR4 & & 0.684 & & \\
\hline SR5 & & 0.736 & & \\
\hline SR6 & & 0.745 & & \\
\hline QoS1 & 0.810 & 0.842 & 0.90 & 0.60 \\
\hline QoS2 & & 0.759 & & \\
\hline QoS3 & & 0.807 & & \\
\hline QoS4 & & 0.779 & & \\
\hline QoS5 & & 0.741 & & \\
\hline QoS6 & & 0.713 & & \\
\hline PSIV1 & 0.773 & 0.709 & 0.77 & 0.53 \\
\hline PSIV2 & & 0.738 & & \\
\hline PSIV3 & & 0.742 & & \\
\hline $\mathrm{SC} 1$ & 0.881 & 0.808 & 0.88 & 0.69 \\
\hline $\mathrm{SC} 2$ & & 0.836 & & \\
\hline SC3 & & 0.783 & & \\
\hline $\mathrm{SC} 4$ & & 0.799 & & \\
\hline PU1 & 0.895 & 0.808 & 0.90 & 0.63 \\
\hline PU2 & & 0.784 & & \\
\hline PU3 & & 0.788 & & \\
\hline PU4 & & 0.791 & & \\
\hline PU5 & & 0.802 & & \\
\hline EoU1 & 0.931 & 0.843 & 0.93 & 0.73 \\
\hline EoU2 & & 0.889 & & \\
\hline EoU3 & & 0.848 & & \\
\hline EoU4 & & 0.874 & & \\
\hline EoU5 & & 0.822 & & \\
\hline A1 & 0.886 & 0.831 & 0.89 & 0.72 \\
\hline A2 & & 0.877 & & \\
\hline A3 & & 0.842 & & \\
\hline BI1 & 0.918 & 0.887 & 0.91 & 0.73 \\
\hline BI2 & & 0.803 & & \\
\hline $\mathrm{BI} 3$ & & 0.875 & & \\
\hline BI4 & & 0.874 & & \\
\hline
\end{tabular}

Table 3. Correlation matrix and discriminant assessment

\begin{tabular}{|c|c|c|c|c|c|c|c|c|c|c|}
\hline Variables & Mean & SD & PMV & SR & QoS & PSIV & UC & $\mathrm{U}$ & EoU & A \\
\hline PMV & 5.39 & 1.33 & & & & & & & & \\
\hline SR & 5.50 & 1.28 & 0.740 & & & & & & & \\
\hline QoS & 5.16 & 1.49 & 0.693 & 0.68 & & & & & & \\
\hline PSIV & 5.59 & 1.21 & 0.778 & 0.682 & 0.696 & & & & & \\
\hline $\mathrm{SC}$ & 5.67 & 1.27 & 0.769 & 0.675 & 0.687 & 0.910 & & & & \\
\hline PU & 5.58 & 1.24 & 0.792 & 0.712 & 0.799 & 0.886 & 0.869 & & & \\
\hline EoU & 5.27 & 1.34 & 0.531 & 0.442 & 0.624 & 0.549 & 0.641 & 0.665 & & \\
\hline A & 5.55 & 1.25 & 0.774 & 0.647 & 0.590 & 0.645 & 0.720 & 0.788 & 0.579 & \\
\hline BI & 5.34 & 1.38 & 0.779 & 0.607 & 0.626 & 0.720 & 0.782 & 0.804 & 0.735 & 0.819 \\
\hline
\end{tabular}


Table 4. Model fit indices

\begin{tabular}{llllllll}
\hline Model fit indices & $\mathrm{x} / \mathrm{dt}$ & GFI & NFI & AGFI & CFI & TLI & RMSEA \\
\hline $\begin{array}{l}\text { Recommended value } \\
\begin{array}{l}\text { Hair } \text { et } \text { al., 2010) } \\
\text { Obtained }\end{array}\end{array}$ & $<3$ & $>0.8$ & $>0.8$ & $>0.8$ & $>0.9$ & $>0.8$ & $<0.08$ \\
\hline
\end{tabular}

Table 5. Summary of hypothesis tests

\begin{tabular}{lllll}
\hline Hypothesis & Path coefficient $(\beta)$ & C.R. (t-value) & p & H-test \\
\hline H1: PMV ----> U & -0.02 & -0.715 & 0.715 & Rejected \\
H2: SR ---> U & 0.36 & 4.336 & $* *$ & Supported \\
H3: SR ----> EoU & -0.06 & -0.736 & 0.462 & Rejected \\
H4: QoS ---> U & 0.28 & 4.167 & $* *$ & Supported \\
H5: QoS ----> EoU & 0.45 & 5.241 & $* *$ & Supported \\
H6: PSIV ----> U & -0.16 & -0.682 & 0.702 & Rejected \\
H7: SC ---> U & 0.60 & 3.931 & $* *$ & Supported \\
H8: SC ----> EoU & 0.44 & 7.687 & $* *$ & Supported \\
H9: EoU ----> U & 0.18 & 3.455 & $* *$ & Supported \\
H10: EoU ----> A & 0.08 & 1.161 & 0.246 & Rejected \\
H11: U ---> A & 0.69 & 8.242 & $* *$ & Supported \\
H12: U ----> BI & 0.48 & 5.957 & $* *$ & Supported \\
H13: A ----> BI & 0.42 & 5.349 & $* *$ & Supported \\
\hline
\end{tabular}

** $\mathrm{p}<0,001$

\section{CONCLUSION}

The results of this study suggest that the external factors of student readiness, quality of service and university commitment are all determinants of mobile learning acceptance. TAM factors of perceived usefulness and perceived ease of use, validated through numerous other studies, were also determined to be significant determinants of mobile learning acceptance. The study revealed that the TAM construct usefulness is the most significant predictor of behavioral intention and thus acceptance. Figure 3 presents the final research model. It presents the explanatory strength of the research model as well as the relationships between the variables investigated. Note that perceived usefulness is a significant predictor of use intention, "82 percent" of perceived usefulness can be interpreted by student readiness, quality of service, system commitment and perceived easy of use. In other words, students' perception of usefulness is not mainly derived from a positive feeling of easy of use $(\beta=0.18)$, the main reason come from student readiness, quality of service, system commitment, specially from system commitment with $\beta=0.6$. In practice, we tend to interpret this finding as follows: The use of mobile phones, especially smart phones today has become easier for everyone. It is also the reason why perceived easy of use didn't impact strongly on the perceived usefulness. Evidence that the number of smartphone users accounted for $20 \%$ of the population of Vietnam (17 million people). So the study results showed that as more and more smartphone users, students in Vietnam enter interesting with the service quality and direct supply from the university system. It also says that the preparation of student ready access to new technologies impact to perceived of usefulness.

Of these factors, system commitment and then perceived usefulness is found to be the strongest determinant of use intention. Hence, an improvement of university system support and perceived usefulness is the key to the success of m-learning, as it will promote both the attitude as well as the usage intention. This is in line with the phenomenon that m-learning for language-studying purpose is popular in Vietnam, as language capability is important for university students in Vietnam in their pursuit of advancement in studies and in their future work.

In this study, we find that perceived mobility value does not affect the usefulness perceived. It's one thing to say that awareness of mobility for usefulness is a truism. With flourished under the mobile phone, users are always aware that mobility really useful at for most cases including m-learning. According to the results in this study, the relationship between Perceived Social Interaction Value and Perceived Usefulness is insignificant. This contradicts the result of previous study conducted by Dickinger et al. (2008). The reason for this might be that students consider social interaction value is not important in mobile learning, since they may already have other approaches to interact with people. 


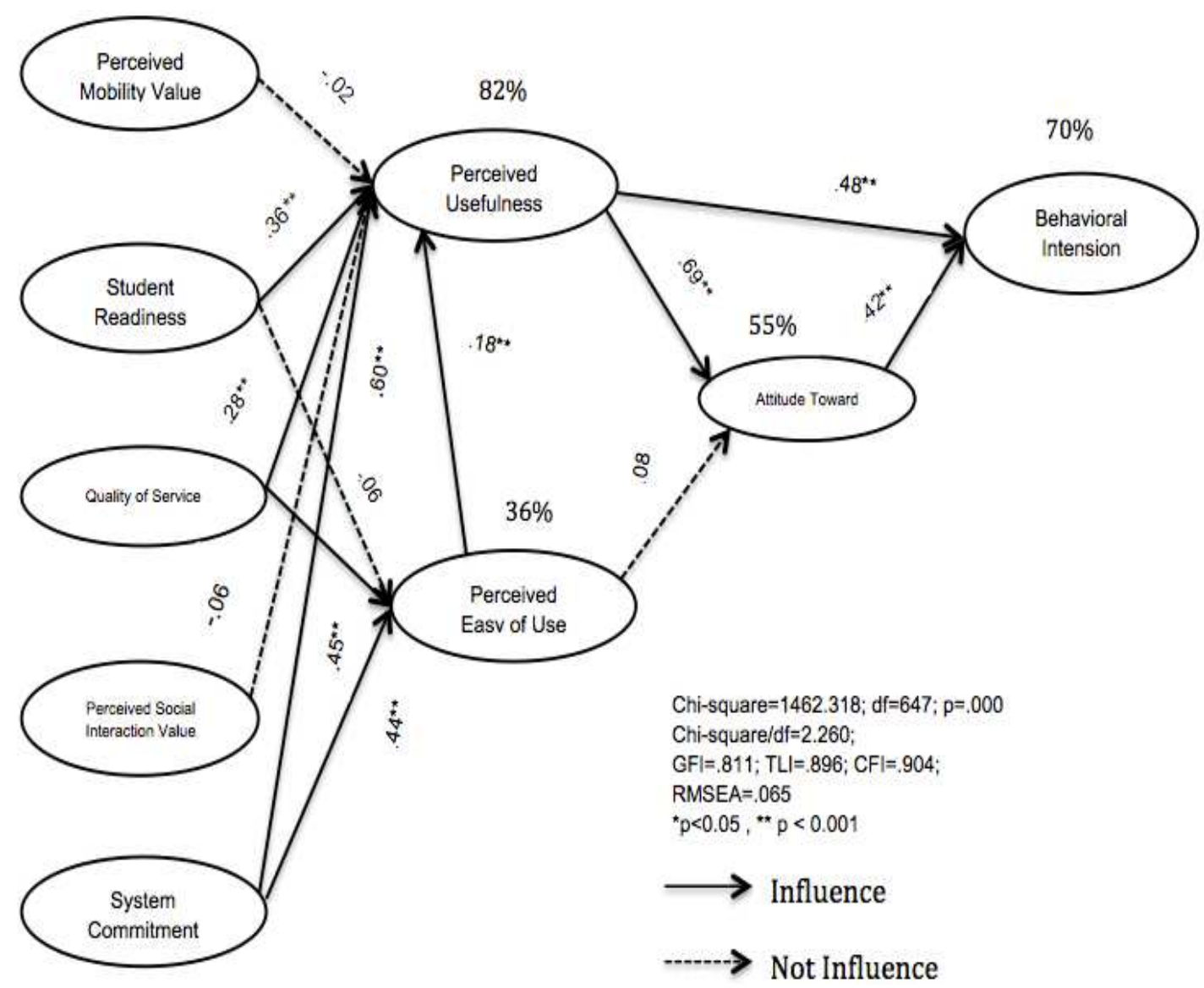

Fig. 3. Research result

The relationship between perceived social interaction value and perceived usefulness was rejected because students show a weak willingness to use mobile devices to interact with classmates and others. The student have been inclined to face-to-face communication for decades and this new form of interaction may cause uncertainty and in adaptation especially in a study context. Group work and discussions are not paid much attention to. Additionally, many students are not active enough to share their thoughts in real-time.

In contrast to previous studies (Li et al., 2008; Legris et al., 2003), a perception of ease of use has no significant effect on m-learning attitude toward. Note that among all the latent variables measured, the mean value of perceived ease of use is much lower than other variables $(\mathrm{PEoU}=5.27)$, as shown in Table 5. It indicates, to some extent, a general feeling that $\mathrm{m}$ learning is not easy to use. Contrary to popular belief in $\mathrm{m}$-learning literature, technological restrictions seem not to induce significant usability problems inhibiting mlearning adoption. This should largely be attributed to the efforts from both mobile manufacturers and learning content designers. In the Vietnam market, a number of devices are specially designed for m-learning purposes; hence, the negative impact of technological restrictions, such as a small screen size and cumbersome input routines, can, to a large degree, be alleviated. Also, there are widespread efforts to design learning software and materials in a manner suitable for handheld usage. As a result, the feeling of ease of use is broadly perceived among students, which show up in the study as an insignificant predictor of m-learning intention. To some extent, the results also indicate that an inclusion of mobile device manufacturers in the provision of $\mathrm{m}$ learning products is a practical and flexible strategy to establish a prosperous m-learning market and this will help to tackle possible technological restrictions in association with perceived ease of use. Based on tests of 
the hypotheses and the hierarchical regression analysis on the TAM constructs, the final model was constructed and explanatory powers were derived. The mobile learning acceptance model (MLAM) was validated and explained a significant portion of the variance in behavioral intention to use mobile learning $(\mathrm{R} 2=70 \%)$. Thus the model developed in this study improves the explanatory power of TAM. TAM2 investigated by Venkatesh and Davis (2000) accounted for 40-60\% of the variance in usefulness perceptions and $34-52 \%$ of the variance in usage intentions. In other studies, variances explained in intention to use were $60 \%$ (Taylor and Todd, 1995), $42 \%$ (Chau and $\mathrm{Hu}, 2001$ ) and $43 \%$ (Chau and $\mathrm{Hu}$, 2002). Additionally, the model explained $82 \%$ of the variance in usefulness, $36 \%$ of the variance in ease of use and $55 \%$ of the variance in attitude.

These results validate the power of TAM constructs and its appropriateness for predicting acceptance of mobile learning. Usefulness had the highest path coefficients and was a strong predictor of behavioral intention and attitude to use and thus actual use. The relationship between ease of use and usefulness was confirmed (Davis, 1989); the other relationships within TAM were also confirmed. Student readiness influenced usefulness directly. Quality of service and system commitment all influenced both usefulness and ease of use directly.

\subsection{Limitations}

This thesis studies and explains students' acceptance towards mobile learning in five top Vietnam universities, based on the proposed TAM model. The factors of the proposed model were tested in a questionnaire-based empirical study, with questions constructed as sevenpoint rating scales (Likert scales). The area of mobile learning acceptance is an emerging area. This research study has contributed to the knowledge base on mobile learning acceptance by building on past empirical and theoretical research. As with all research, we acknowledge some limitations in this study that should be considered. First The Scope of the study is limited to universities in Ho Chi Minh city (Vietnam) setting and thus the results could have limited generalizability, the results should not be generalized to m-learning users in different age groups or with other cultural backgrounds. Second, It is expected that most students have not experienced actual mobile learning services. Therefore they will use their knowledge and perceptions to comment on mobile learning. Furthermore, since it is assumed that students have basic knowledge of mobile devices, computers and the Internet, the use of students as the sample frame in this study can decrease the effect of mobile and computer literacy variances. Third, this study does not investigate actual usage but rather prediction of use through intention. Although this is a limitation, the causal link between intention and actual behavior has been substantially empirically supported through prior research (Venkatesh and Davis, 2000; Taylor and Todd, 1995; Davis, 1989). Finally, the research model was limited to investigating the external variables as exogenous variables where they cannot act as mediators. This resulted in the exclusion of the construct of ease of access from the predictive model. Note that, adoption is just a first step of m-learning success in Vietnam; there is also a need to find out how to make the use of m-learning methods and technology continuous.

\section{ACKNOWLEDGMENT}

Financial support from the Korea IT service Foundation is gratefully acknowledged. This work was also supported by the SNS Innovation Lab, Soongsil University, Business Administration department. The successful completion of this paper would not have been possible without the guidance and support offered by several key individuals. Special thanks to Professor Gwangyong Gim, for patiently examining our Empirical Study and providing precious comments and suggestions. The authors would like to thank anonymous reviewers for their constructive comments.

\section{REFERENCES}

Adkins, S.S., 2008. The US market for mobile learning products and services: 2008-2013 forecast and analysis. Ambient Insight, LLC.

Ajzen, I. and M. Fishbein, 1980. Understanding Attitudes and Predicting Social Behavior. 1st Edn., Prentice-Hall, Englewood Cliffs, ISBN-10: 0139364439, pp: 278.

Attewell, J. and C. Savill-Smith, 2003. M-learning and social inclusion-focusing on learners and learning. Proceedings of the Conference on Learning with Mobile Devices, (LMD' 03), Learning and Skills Development Agency, London, UK., pp: 3-12.

Bandura, A., 1977. Self-efficacy: Toward a unifying theory of behavioral change. Psychol. Rev., 84: 191215. DOI: $10.1037 / 0033-295 X .84 .2 .191$

Bandura, A., 1982. Self-efficacy mechanism in human agency. Am. Psychol., 37: 122-147. DOI: 10.1037/0003-066X.37.2.122 
Barnes, S. and R. Vidgen, 2002. An integrative approach to the assessment of e-commerce quality. J. Electr. Commerce Res., 3: 114-127.

Chau, P.Y.K. and P.J. Hu, 2001. Information technology acceptance by individual professionals: A model comparison approach. Decision Sci., 32: 699-719. DOI: 10.1111/j.1540-5915.2001.tb00978.x

Chau, P.Y.K. and P.J. Hu, 2002. Investigating healthcare professionals' decisions to accept telemedicine technology: An empirical test of competing theories. Inform. Manage., 39: 297-311. DOI: 10.1016/S0378-7206(01)00098-2

Chun, C.H. and C. Yang, 2011. The intellectual development of the technology acceptance model: A co-citation analysis. Int. J. Inform. Manage., 31: 128-136. DOI: 10.1016/j.ijinfomgt.2010.07.003

Compeau, D.R. and C.A. Higgins, 1995. Computer selfefficacy: Development of a measure and initial test. MIS Q., 19: 189-211. DOI: 10.2307/249688

Davis, F.D., 1989. Perceived usefulness, perceived ease of use and user acceptance of information technology. MIS Q., 13: 319-340.

Delone, W. and E. Mclean, 1992. Information systems success: The quest for the dependent variable. Inform. Syst. Res., 3: 60-95. DOI: 10.1287/isre.3.1.60

Dickinger, A., M. Arami and D. Meyer, 2008. The role of perceived enjoyment and social norm in the adoption of technology with network externalities. Eur. J. Inform. Syst., 17: 4-11. DOI: 10.1057/palgrave.ejis.3000726

Fornell, C.D. and F. Larcker, 1981. Evaluating structural equation models with unobservable variables and measurement errors. J. Market. Res., 18: 39-50. DOI: $10.2307 / 3151312$

Hair, J.F., R.E. Anderson, R.L. Tatham and W.C. Black, 1998. Multivariate Data Analysis with Readings. 1st Edn.,Prentice Hall, Upper Saddle River, NJ.

Hair, J.F., R.E. Anderson, R.L. Tatham and W.C. Black, 2010. Multivariate Data Analysis with Readings. 1st Edn., Macmillan, New York.

Huang, J., Y. Lin and S. Chuang, 2007. Elucidating user behavior of mobile learning: A perspective of the extended technology acceptance model. Electr. Library, 25: 585-598. DOI: 10.1108/02640470710829569

Igbaria, M., 1990. End-user computing effectiveness: A structural equation model. Omega, 18: 637-652. DOI: 10.1016/0305-0483(90)90055-E
Igbaria, M., 1993. User acceptance of microcomputer technology: An empirical test. Omega, 21: 73-90. DOI: 10.1016/0305-0483(93)90040-R

Keegan, D., 2002. The future of learning: From eLearning to mLearning. Institute for Research into Distance Education.

Kuan, H.H., V. Vathanophas and G.W. Bock, 2003. The Impact of usability on the intention of planned purchases in e-commerce service websites. Proceedings of the 7th Pacific Asia Conference on Information Systems, Jul. 10-13, Adelaide, South Australia, pp: 369-392.

Lee, M.C. and T.R. Tsai, 2010. What drives people to continue to play online games? An extension of technology model and theory of planned behavior. Int. J. Human-Comput. Interact., 26: 601-620. DOI: 10.1080/10447311003781318

Legris, P., J. Ingham and P. Collerette, 2003. Why do people use information technology? A critical review of the technology acceptance model. Inform. Manage., 40: 191-204. DOI: 10.1016/S03787206(01)00143-4

Li, Y., J. Qi and H. Shu, 2008. Review of relationships among variables in TAM. Tsinghua Sci. Technol., 13: 73-278. DOI: 10.1016/S1007-0214(08)70044-0

Lin, C.S. and S. Wu, 2002. Exploring the impact of online service quality on portal site usage. Proceedings of the 35th Annual Hawaii International Conference on System Sciences, Jan. 7-10, IEEE Xplore Press, pp: 2654-2661. DOI: 10.1109/HICSS.2002.994223

Little, J., 2006. What we're learning from our mobility project(s). The University of Tennessee.

Liu, C. and K. Arnett, 2000. Exploring the factors associated with Web site success in the context of electronic commerce. Inform. Manage., 38: 23-33. DOI: 10.1016/S0378-7206(00)00049-5

Lopez, D.A. and D.P. Manson, 1997. A study of individual computer self-efficacy and perceived usefulness of the empowered desktop information system. J. Interdisciplinary Stud., 10: 83-83.

Moore, G. and I. Benbasat, 1991. Development of an instrument to measure the perceptions of adopting an information technology innovation. Inform. Syst. Res., 2: 192-222. DOI: 10.1287/isre.2.3.192

Nielson, G.M., 1993. Scattered data modeling. IEEE Comput. Graph. Applic., 13: 60-70. DOI: $10.1109 / 38.180119$ 
Parasuraman, A., V. Zeithaml and A. Malhotra, 2005. ES-Qual: A multiple-item scale for assessing electronic service quality. J. Service Res., 7: 213233. DOI: $10.1177 / 1094670504271156$

Parasuraman, A., V. Zeithaml and L. Berry, 1994. Reassessment of expectations as a comparison standard in measuring service quality: Implications for further research. J. Market., 58: 111-124.

Park, Y. and J. Chen, 2007. Acceptance and adoption of the innovative use of smartphone. Indust. Manage. Data Syst., 107: 1349-1365. DOI: 10.1108/02635570710834009

Rai, A., S. Lang and R. Welker, 2002. Assessing the validity of IS success models: An empirical test and theoretical analysis. Inform. Syst. Res., 13: 50-69. DOI: $10.1287 /$ isre.13.1.50.96

Seppälä, P. and H. Alamäki, 2003. Mobile learning in teacher training. J. Comput. Assisted Learn., 19: 330-335. DOI: 10.1046/j.0266-4909.2003.00034.X
Taylor, S. and P.A. Todd, 1995. Understanding information technology usage: A test of competing models. Inform. Syst. Res., 6: 144-176. DOI: 10.1287/isre.6.2.144

Thompson, R., C. Higgins and J. Howell, 1994. Influence of experience on personal computer utilization: Testing a conceptual model. J. Manage. Inform. Syst., 11: 167-187.

Trifonova, A., 2003. Mobile learning-review of the literature. Technical Report DIT- 03-009, Informatica e Telecomunicazioni, University of Trento.

Venkatesh, V. and F.D. Davis, 2000. A theoretical extension of the technology acceptance model: Four longitudinal field studies. Manage. Sci., 46: 186204. DOI: $10.1287 / \mathrm{mnsc} .46 .2 .186 .11926$ 